\title{
HIGHLY RESOLVED DIRECTIONAL PROPERTIES OF WIND WAVES AND SWELL WITH VARIOUS SCALES
}

Takashi Fujiki, Port and Airport Research Institute, fujiki-t@pari.go.jp

Koji Kawaguchi, Port and Airport Research Institute, kawaguchi-k@pari.go.jp

Fumikazu Suehiro, Port and Airport Research Institute, suehiro-f82ab@pari.go.jp

Noriaki Hashimoto, Kyushu University, hashimoto-n@civil.kyushu-u.ac.jp

\begin{abstract}
INTRODUCTION
Wave directional spectrum is basic information as the forcing on the coastal process. The directional properties of coastal waves have been widely investigated through observations and the results are applied for design use of coastal structures and implementation of numerical wave model. But these studies focused only on wind waves under moderate sea conditions because the limitations of instruments such as buoys and wave staffs make them unsuitable for observing under various sea conditions including the severe sea. Thus there are few systematic studies for coastal engineering application which needs treatment for various sea state, from modest to severe sea. In this study, we observed the wave directional spectrum with the bottom mounted ADCP (Acoustic Doppler Current Profiler) which can record even under severe conditions. We investigated the directional properties of wind waves and swell with various scales.
\end{abstract}

\section{INSTRUMENTS AND ANALYSIS TECHNIQUES}

We analyzed wave data observed by the ADCPs in Japan coast for a year in 2015. ADCPs used in this study were enhanced to collect velocity measurements at 10 selected depth cell. To obtain the wave directional spectrum with higher resolution, we used the Bayesian directional method to infer the wave directional spectrum from a large number of array elements. To separate the wind sea and swell from the observed wave directional spectrum, we used $U_{10} / C_{\text {peak }}$ (inverse wave age) as the index which represents the wind contribution to waves. To calculate $U_{10} / C_{\text {peak }}$, wind data recorded at the light house in the vicinity of wave observation points were available. We excluded marginal data with several criteria to reject samples under the unsteady wave and meteorological condition. The details of observation points, instruments, analysis techniques and the criteria will be described in the presentation.

\section{RESULTS}

(1) Separation of Wind Sea and Swell: We obtained 103 samples of various scale waves in Table.1.; 50 in wind sea and 53 in the swell. In Figure.1, we examined the $3 / 2$ power law proposed for wind waves with all 103 samples to validate the separation of wind sea and swell with our criteria. We confirmed samples in wind sea follow the single curve of $3 / 2$ power law but ones in swell tend to deviate from such the curve. (2) Directional Properties and Its Dependence: We showed the dependence of $\overline{\sigma_{\theta}(f)}$ (mean directional spread) on $H_{m 0} / L_{\text {peak }}$ (wave steepness) in Figure.2. With the data presented here, mean directional spread in wind sea increase as wave steepness increase, but in contrast, one in swell decrease.

\section{CONCLUSIONS}

We investigated the directional properties of highly resolved directional spectrum for wind sea and swell with various scales. We indicated the dependence of directional properties of the swell on wave steepness can be different from ones of wind sea.

Table 1 - Summary of Samples of Wind Sea and Swell

\begin{tabular}{|c|c|c|c|}
\hline & $H_{m 0}(\mathrm{~m})$ & $T_{\text {peak }}(\mathrm{s})$ & $U_{10} / C_{\text {peak }}(-)$ \\
\hline wind sea & $0.62^{\sim} 5.21$ & $4.4^{\sim 11.5}$ & $0.93^{\sim} 1.69$ \\
\hline swell & $0.50^{\sim} 4.18$ & $5.8^{\sim} 15.8$ & $0.16^{\sim} 0.50$ \\
\hline
\end{tabular}

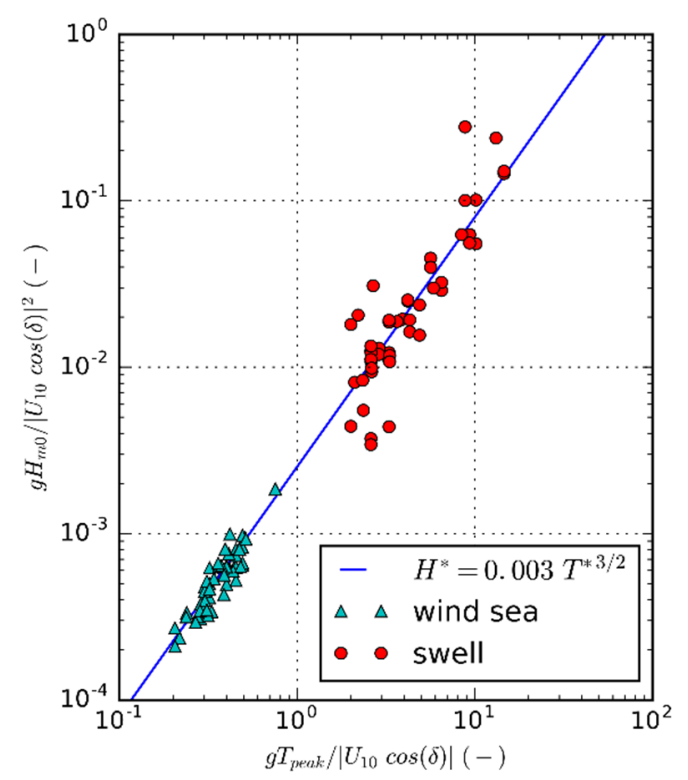

Figure 1 - Dimensionless Wave Height and Wave Period

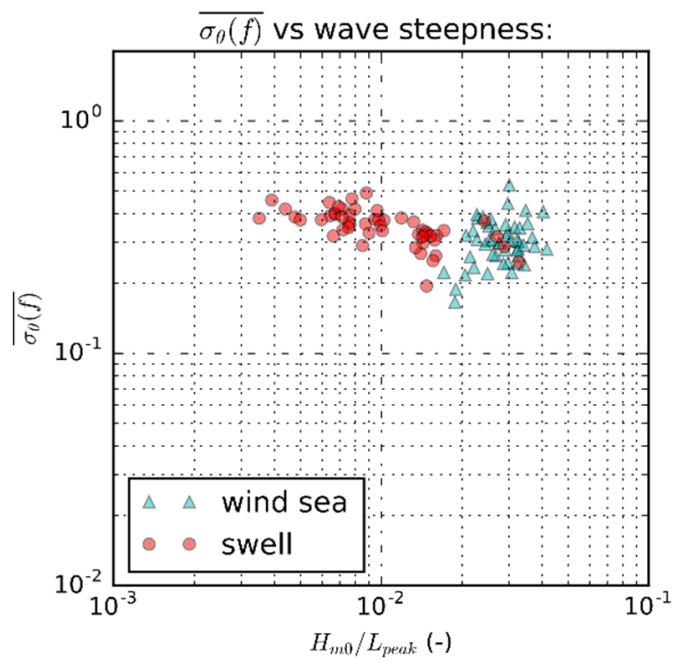

Figure 2 - Wave Steepness and Mean Directional Spread

\section{ACKNOWLEDGEMENT}

The present study was supported by JSPS KAKENHI (Grant Number 17H03315). 